\title{
Physical Activity Patterns Among Resident and Staff Physicians in Hamilton Teaching Hospitals
}

Oren Steen, MD, Ally P.H. Prebtani, MD

\begin{abstract}
About the Authors
Oren Steen is a recent graduate of the Endocrinology and Metabolism Residency Training Program at McMaster University in Hamilton, Ontario. Ally Prebtani is a staff endocrinologist and program director of the Endocrinology and Metabolism Residency Training Program at McMaster University. Correspondence may be directed to oren. steen@medportal.ca.
\end{abstract}
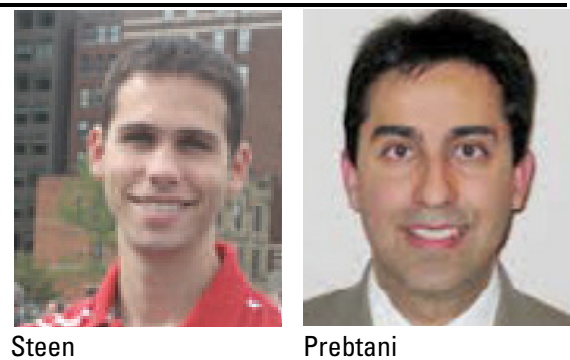

\section{Summary}

Objective: This study aimed to evaluate patterns of, and barriers to, physical activity between resident and staff physicians in Hamilton teaching hospitals.

Methods: A total of 300 physicians were enrolled in this cross-sectional study that involved an online questionnaire containing 34 questions.

Results: The average participant reported 164 minutes per week of moderate to strenuous physical activity. There were no significant differences between resident and staff physicians (154 vs. 185 minutes per week; $P$ $=0.15)$, between men and women (177 vs. 155 minutes per week; $P=0.31)$, among the various specialties $(P=0.54)$, by number of children $(P=0.63)$, or by exercise counselling practices $(P=0.75)$. Within the age categories, those aged 35 to 44 years exercised significantly less than the group aged 45 to 54 years (110 vs. 231 minutes per week; $P=0.01$ ). The most commonly cited barriers to physical activity included feeling too tired to exercise after work, the time required for exercise, family responsibilities, and unfavourable weather conditions.

Conclusion: The average physician who responded to our survey reported physical activity patterns meeting current Canadian Society for Exercise Physiology (CSEP) recommendations regarding physical activity. Numerous barriers to exercise have been cited. More efforts are needed to minimize these barriers, implement strategies for increasing physical activity, and better promote physician health and wellness.

\section{Résumé}

La présente étude a pour but d'évaluer le degré et les modalités d'activité physique des résidents et des médecins en poste dans les hôpitaux universitaires de Hamilton, ainsi que les obstacles à l'activité physique. Cette étude transversale a été menée auprès de 300 médecins devant remplir un questionnaire en ligne (34 questions). Elle constate que l'activité physique dont font état les participants est conforme en général aux recommandations de la Société canadienne de physiologie de l'exercice. Les participants ont mentionné de nombreux obstacles entravant l'activité physique. Des initiatives devront être entreprises pour surmonter ces obstacles, mettre en œuvre des stratégies d'augmentation de l'activité physique et mieux promouvoir la santé et le bien-être du médecin. 


\section{Introduction}

Over the last number of decades, obesity prevalence has increased in Canada. Between 1985 and 2011, the prevalence of adult obesity in Canada rose from $6.1 \%$ to $18.3 \%$. $^{1}$ The consequences have posed a significant burden on our health care system. ${ }^{2}$ For instance, the prevalence of metabolic syndrome was found to be $19.1 \%$, with abdominal obesity being the most common component of the syndrome. ${ }^{3}$ Although medications are effective in treating cardiovascular risk factors, lifestyle interventions as a first-line approach are often overlooked.

Regular physical activity is an important component in maintaining a healthy body weight. The Canadian Society for Exercise Physiology (CSEP) recommends at least 150 minutes per week of moderate to strenuous intensity aerobic activity (or 75 minutes of strenuous activity) for optimal health. ${ }^{4}$

Physicians tend to have numerous professional and personal commitments. Consequently, their personal health and wellbeing are frequently neglected. ${ }^{5}$ Increasing emphasis is now being directed towards physician health. Most of the research pertaining to the latter has focused on work-related stress and burnout, mental health, and substance abuse. ${ }^{5}$ Less research has been conducted examining lifestyle habits and preventive health measures among physicians.

The 2007 Physician Health Survey is the largest Canadian study to date focusing on physician health. It found that physicians exercised on average 4.7 hours per week, $58 \%$ of which was of moderate or strenuous intensity. ${ }^{6}$ They therefore averaged 164 minutes per week of moderate to strenuous exercise.

This study aimed to evaluate how Hamilton resident and staff physicians measured up to the national standard. Barriers to physical activity were also explored, something that has not been previously studied among physicians.

\section{Subjects and Methods}

\section{Study Population and Data Collection}

This cross-sectional study was conducted between February 22, 2013 and April 15, 2013. All postgraduate residents and staff physicians affiliated with McMaster University were invited by email to participate in the study. A reminder email was sent three weeks after the initial invitation.

Data on demographics, frequency and duration of physical activity (for mild, moderate, and strenuous activity), barriers to physical activity, and beliefs regarding the importance of physical activity were collected anonymously using SurveyMonkey ${ }^{\circledR}$, a web-based survey tool.

Ethics approval was obtained from the Hamilton Integrated Research Ethics Board. Informed online consent was obtained from all subjects.

\section{Questionnaire}

Our survey included 34 questions. A copy of the survey can be found in the online appendix. The questionnaire included many of the relevant survey questions used in the National Physician Health Survey by Frank and Segura. ${ }^{6}$ Their survey was created with input from various physicians' associations. ${ }^{6}$ A vast number of these questions were derived from the Canadian Community Health Survey, the National Survey of the Work and Health of Nurses, and the Behavioural Risk Factor Surveillance system, so that various comparisons can be made. ${ }^{6}$ Many of the questions pertaining to physical activity barriers derive from the Exercise Benefits/Barriers Scale developed by Sechrist and colleagues. ${ }^{7}$

\section{Statistical Analysis}

Student's $t$ test was used to evaluate differences in moderate to strenuous physical activity (described in questions \#14 and \#16 in the online appendix) between resident and staff physicians and between male and female sex. One-way analysis of variance (ANOVA) was performed to assess for differences in physical activity among specialties as well as age categories. Categories with sample sizes less than five were excluded from the analysis. A $P$ value of $<0.05$ was considered statistically significant. Tukey's post-hoc test was used when the ANOVA was statistically significant. Fisher's exact test was used to compare differences in the prevalence of overweight and obesity between male and female sex. Statistical analyses were performed with Statistical Package for the Social Sciences version 20.0 software (SPSS Inc.).

\section{Results \\ Demographic Data}

A total of 300 physicians were recruited into the study. Of 800 postgraduate residents, 204 participated in the study, for a response rate of $26 \%$. A total of 96 staff physicians took part in the study. Because staff email invitations went channelled through various departments, we were unable to determine their exact response rate.

The average physician responding to our survey reported 164 minutes per week of moderate to strenuous physical activity. Demographic information is summarized in Table 1.

\section{Amount of Physical Activity}

The distribution of moderate to strenuous physical activity patterns can be seen in Figure 1. There were no significant differences between resident and staff physicians (154 vs. 185 minutes per week; $P=0.15$ ), between men and women (177 vs. 155 minutes per week; $P=0.31$ ), among the various specialties $(P=0.54)$, by number of children $(P=0.63)$, or 


\begin{tabular}{|l|c|c|}
\multicolumn{2}{|c|}{$n$} & \% of respondents \\
\hline $\begin{array}{l}\text { Appointment } \\
\text { Resident } \\
\text { Staff }\end{array}$ & 204 & 68 \\
\hline Specialty & 96 & 32 \\
\hline Surgical & & \\
Non-surgical & 45 & 16.5 \\
\hline Gender & 228 & 83.5 \\
\hline Male & & \\
Female & 131 & 43.8 \\
\hline Age category & 168 & 56.2 \\
\hline$<35$ & & \\
$35-44$ & 191 & 63.7 \\
$45-54$ & 46 & 15.3 \\
$55-64$ & 40 & 13.3 \\
$\geq 65$ & 21 & 7.0 \\
\hline Number of children & 2 & 0.7 \\
0 & & \\
\hline 1 & 182 & 61.1 \\
$\geq 2$ & 30 & 10.1 \\
\hline BMI (kg/m2) & 86 & 28.9 \\
\hline 25.0 & & \\
$25.1-29.9$ & 198 & 2.9 \\
$\geq 30$ & 74 & \\
\hline
\end{tabular}

Table 1 Demographic data $(n=300)$

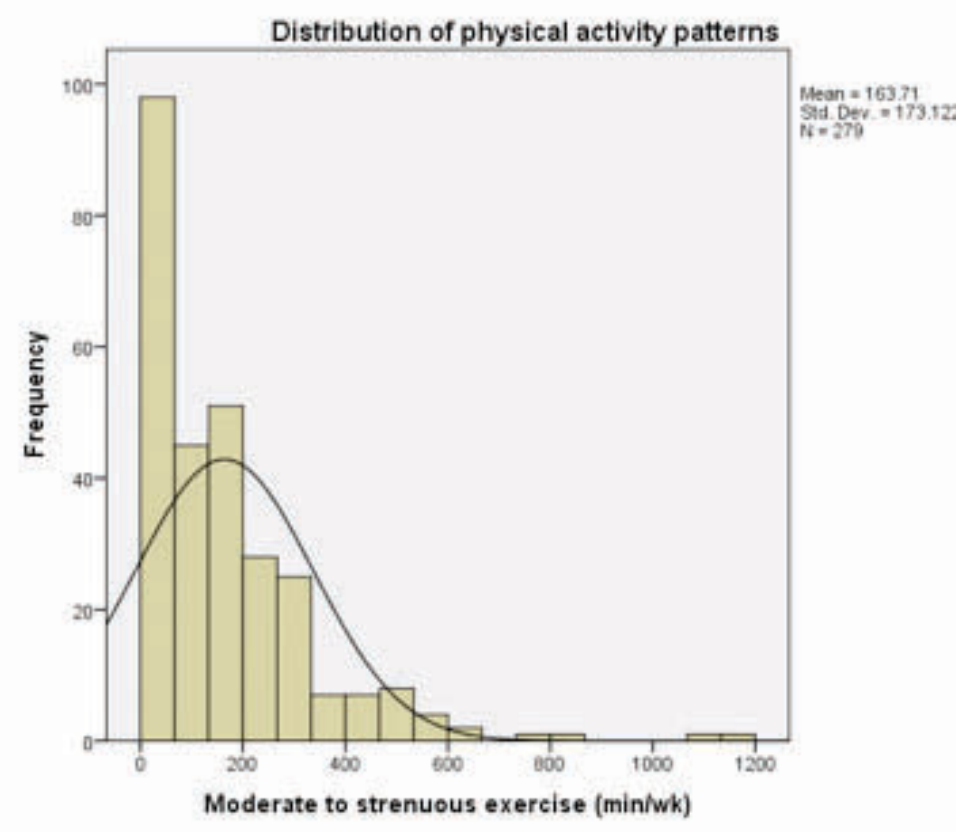

Figure 1. Histogram showing the distribution of moderate to strenuous physical activity patterns by exercise counselling practices $(P=0.75)$. Physical activity varied significantly by age group, and when analyzed with Tukey's post-hoc test, the group aged 35 to 44 years and 45 to 54 years was significantly different (110 vs. 231 minutes per week; $P=0.01$ ). Overall, $50.7 \%$ of physicians reported over 150 minutes per week of moderate to strenuous physical activity. Of these, $12.0 \%$ exercised 150 to 160 minutes per week.

\section{Barriers to Physical Activity}

Barriers to physical activity are summarized in Table 2 . The most commonly cited barriers included feeling too tired to exercise after work, the time required for exercise, family responsibilities, and unfavourable weather conditions. The least commonly cited barriers were injury and embarrassment about exercising.

\section{Attitudes Regarding Importance of Physical Activity}

A total of $35.6 \%$ of respondents reported they usually or always talk to their patients about physical activity, while $45.9 \%$ sometimes do, and $18.5 \%$ never or rarely do. Fifty-five percent of subjects value physical activity "very much," with regards to their general well-being.

\section{Strategies to Increase Physical Activity}

Various strategies employed for increasing physical activity are outlined in Table 3. Those reported most frequently include taking the stairs rather than the elevator, doing regular vigorous housework, parking as far from the entrance as possible, and walking, jogging, or cycling to work. Among the other strategies mentioned were employing personal trainers, working out at home, varying exercise routines, walking the dog, exercising early in the morning before work, and exercising with friends.

\section{Other Data}

The prevalence of overweight and obesity was significantly higher in men compared to women $(40.5 \%$ vs. $21.0 \%$; $\mathrm{P}<$ $0.05)$. Less than half $(44.3 \%)$ of respondents had active gym memberships. However, most subjects (71.9\%) felt they would be more likely to exercise if their hospital had gym and shower facilities. A total of $94.3 \%$ of subjects reported being in good general health, although $71.5 \%$ felt they do not get enough physical activity.

\section{Discussion}

The average physician responding to our questionnaire reported 164 minutes per week of moderate to strenuous physical activity, which was in line with the 2007 National Physician Health Survey conducted by Frank and Segura. ${ }^{6}$ 


\begin{tabular}{|l|c|}
\hline Statement & $\begin{array}{c}\% \text { of } \\
\text { respondents }\end{array}$ \\
\hline I feel too tired to exercise after work & $70.4 \%$ \\
\hline Exercising takes up too much of my time & $45.7 \%$ \\
\hline $\begin{array}{l}\text { Exercise takes too much from my family } \\
\text { responsibilities }\end{array}$ & $33.8 \%$ \\
\hline I find it difficult to exercise due to unfavourable & $31.9 \%$ \\
\hline weather conditions & \\
\hline Exercise facilities do not have convenient schedules & $30.5 \%$ \\
\hline for me & $25.5 \%$ \\
\hline Exercise tires me & $24.0 \%$ \\
\hline Exercise is hard work for me & $22.1 \%$ \\
\hline I find exercise boring & $21.7 \%$ \\
\hline Places for me to exercise are too far away & $17.8 \%$ \\
\hline I lack a partner with whom to exercise & $15.3 \%$ \\
\hline There are too few places for me to exercise & $15.0 \%$ \\
\hline I lack exercise equipment & $12.1 \%$ \\
\hline It costs too much money to exercise & $9.3 \%$ \\
\hline My family members do not encourage me to exercise & $8.6 \%$ \\
\hline My spouse (or significant other) does not encourage & $5.2 \%$ \\
\hline exercising & $3.2 \%$ \\
\hline I am unable to exercise due to injury & \\
\hline I am too embarrassed to exercise & \\
\hline I think people in exercise clothes look funny & \\
\hline
\end{tabular}

Table 2 Barriers to physical activity

\begin{tabular}{|l|c|}
\hline Strategy & $\begin{array}{c}\text { Percent of } \\
\text { respondents } \\
\text { employing } \\
\text { strategy }\end{array}$ \\
\hline I generally take the stairs rather than the elevator & $94.3 \%$ \\
\hline I do regular vigorous housework & $25.5 \%$ \\
\hline I park as far from the front door as possible & $22.1 \%$ \\
\hline I walk/jog/cycle to work & $22.1 \%$ \\
\hline I do gardening & $18.6 \%$ \\
\hline I break up my exercise sessions into several short & $16.0 \%$ \\
\hline blocks & $9.5 \%$ \\
\hline I am in a walking/jogging/cycling group & $6.5 \%$ \\
\hline I take a brisk walk at lunchtime & $5.0 \%$ \\
\hline I am too embarrassed to exercise & $3.2 \%$ \\
\hline I think people in exercise clothes look funny & \\
\hline
\end{tabular}

Table 3 Strategies used to increase physical activity
Interestingly, there were no significant differences in amount of physical activity among the various specialties. Those specialties with longer work hours might have been expected to exercise less than those with lighter work schedules. For instance, in a study by Kumagai and Ogura, longer work hours in middle-aged Japanese workers had negative effects on regular physical activity participation. ${ }^{8}$ Another notable finding was that participants aged 35 to 44 years exercised less than half that of those aged 45 to 54 years. One might postulate that those aged 35 to 44 years were preoccupied with raising a young family and thus more limited by family commitments than their 45- to 54-year-old counterparts.

Time appeared to be a common barrier to physical activity, not surprisingly. This was also found to be the case in an Australian adult survey by Booth and colleagues, with lack of motivation and childcare responsibilities following suit. ${ }^{9}$ Disappointingly, just over one-third of physicians regularly counselled their patients on physical activity. For many conditions, lifestyle recommendations should be discussed before initiating (or concurrent with) pharmacological treatment. Contrary to the study by Frank and others, ${ }^{10}$ this study did not find that physicians who regularly counselled their patients on exercise were most likely to be physically active themselves.

The reported rates of overweight and obesity were lower in this study, compared to the 2007 Physician Health Survey (29.3\% vs. $45 \%) .^{9}$ As well, the rates in men were almost double that of women ( $40.5 \%$ vs. $21.0 \%)$. This proportion was similar in the 2007 Physician Health Survey, where 55\% of male physicians reported being either overweight or obese, compared to $25 \%$ of female physicians. ${ }^{9}$

A total of $71.5 \%$ of subjects felt they do not get enough physical activity. A similar percentage of respondents felt they would be more likely to exercise if their hospital had gym and shower facilities. Creating a hospital-based gym is an undertaking worth further exploring and one that other hospitals have accomplished in recent years.

\section{Limitations}

Some limitations warrant consideration. Our data relied on self-reporting, which limits its reliability. The resident response rate of $26 \%$ was suboptimal. Unfortunately, we were unable to determine how many staff physicians received the email invitation for the survey, as it was streamlined through numerous departments. The small sample size served to decrease the study's power. It is also conceivable that there was selection bias, as those with a stronger interest in physical activity might have been more likely to complete 
the questionnaire. Finally, as with any observational study, multiple confounders may have impacted the results.

\section{Conclusion}

On average, the physicians responding to our questionnaire reported 164 minutes per week of physical activity. Moreover, their exercise patterns are similar to those reported in the 2007 Physician Health Survey. Those in the group aged 35 to 44 years exercised significantly less than their 45 - to 54-yearold counterparts. Otherwise, no significant between-group differences were found. However, because these results represent a small sample of McMaster University physicians, they may not be generalizable to the population as a whole. Numerous barriers to exercise have been cited. More efforts are needed to minimize these barriers, implement strategies for increasing physical activity, and better promote physician health and wellness.

Acknowledgements: The authors acknowledge Dr. Zubin Punthakee for critically reviewing the manuscript, as well as Dr. Erica Frank for providing a copy of the "Health Practices of Canadian Physicians" survey used in the 2007 Physician Health Study.

\section{References}

1. Twells LK, Gregory DM, Reddigan J, et al. Current and predicted prevalence of obesity in Canada: a trend analysis. CMAJ 2014;2:E18-26.

2. Wanner M, Götschi T, Martin-Diener E, et al. Active transport, physical activity, and body weight in adults: a systematic review. Am J Prev Med 2012;42:493-502.

3. Riediger ND, Clara I. Prevalence of metabolic syndrome in the Canadian adult population. CMAJ 2011;183:E1127-34.

4. Tremblay MS, Warburton DE, Janssen I, et al. New Canadian physical activity guidelines. Appl Physiol Nutr Metab 2011;36:47-58.

5. Tyzuk K. Physician health: a review of lifestyle behaviors and preventive health care among physicians. BCMJ 2012;54:419-23.

6. Frank E, Segura C. Health practices of Canadian physicians. Can Fam Physician 2009;55:810-11.e7.

7. Sechrist KR, Walker SN, Pender NJ. Development and psychometric evaluation of the Exercise Benefits/Barriers Scale. Res Nurs Health 1987;10:357-65.

8. Kumagai N, Ogura S. Persistence of physical activity in middle age: a nonlinear dynamic panel approach. Eur J Health Econ 2013;Jul 17. [Epub ahead of print].

9. Booth ML, Bauman A, Owen N, et al. Physical activity preferences, preferred sources of assistance, and perceived barriers to increased activity among physically inactive Australians. Prev Med 1997;26:131-7.

10. Frank E, Segura C, Shen H, et al. Predictors of Canadian physicians' prevention counselling practices. Can J Public Health 2010;101:390-5.

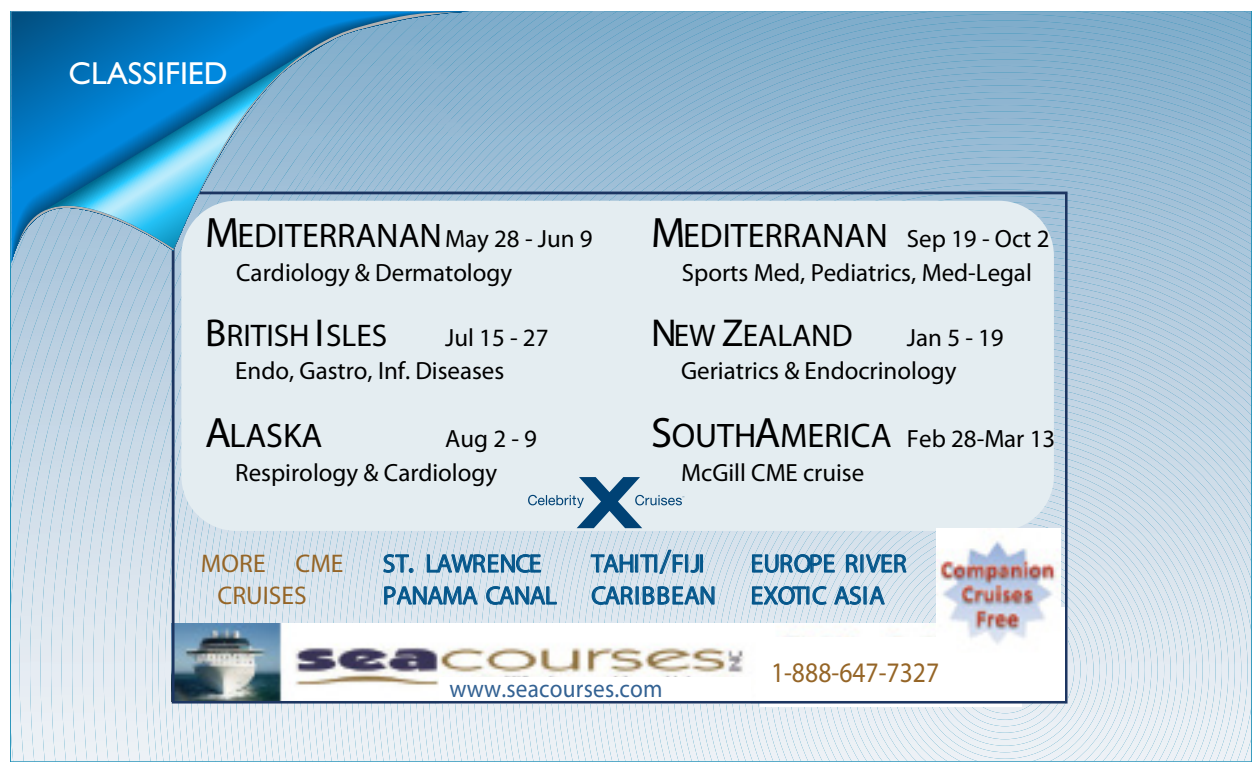

